\title{
Healthy Udders and Feet \& Legs = Healthy Cows \& Happy Dairy Producers
}

\author{
Leo L. Timms ${ }^{1}$
}

\begin{abstract}
Optimizing animal health and performance is critical for quality, safe dairy products and the economic vitality of dairy operations. Producing both high quality and quantities of milk is the main income side of dairies and crucial for economic success, so attention to optimizing animal nutrition and care and practicing proper milk harvesting practices is essential. Bovine mastitis is one of the most economically expensive diseases of dairy cattle. Proper and rapid identification of mastitis problems and cows (clinical and subclinical) is critical and programs for both prevention and appropriate therapy including culling of problem cows are important for maximizing udder health. Lameness is dairy cattle is another of the top 3 dairy health expenses that leads to decreased production and performance, and often premature culling from dairy herds. Like mastitis, proper and rapid lameness identification coupled with appropriate prevention programs and therapy strategies are critical for dairy economic success.
\end{abstract}

Key words: Lameness, mastitis.

\section{Ubres, Patas y Piernas Saludables = Vacas Sanas y Productores Contentos}

Resumen. La optimización de la sanidad y rendimiento animal es crítico para productos de calidad y seguros y la vitalidad económica de las operaciones lecheras. La producción de leche de alta calidad y cantidad es el ingreso principal de lecherías y es crucial para el éxito económico, por esto la atención a la optimización de la nutrición animal y la práctica apropiada de ordeño es esencial. La mastitis bovina es una de las enfermedades más costosas del ganado lechero. La apropiada y rápida identificación de mastitis (clínica y subclínica) es crítica y los programas para su prevención y tratamiento apropiado, incluyendo la eliminación de vacas problemáticas, son importantes para maximizar la sanidad de la ubre. La renquera en ganado de leche es otra de las principales tres problemas de sanidad que reduce la producción y rendimiento, y normalmente a la eliminación prematura del hato. Como la mastitis, la identificación apropiada y rápida de renquera en conjunto con programas apropiados de prevención y estrategias de tratamiento son críticos para una buena economía lechera.

Palabras clave: Mastitis, renquera.

\section{Time Budgets of Dairy Cows}

In order to optimize animal health of dairy cattle, it is essential to understand the daily time budgets of these animals and provide an environment and practices which allow the animal to achieve these times and optimize productivity while minimizing health risks and diseases. While the actual time to milk animals and the amount of time drinking water are both only about 30 minutes/day, providing excellent milking practices and adequate quantities of high quality water are essential pillars for animal health success (Figure 1 ). Dairy cows eat about 6 hours/day and proper nutrition and adequate space and environment are essential for animal productivity while also optimizing immunity and animal health. Dairy cows must also travel and walk places so attention to proper feet and leg health coupled to an environment and facilities that optimize leg health (clean, sound walking surfaces) is crucial. Finally, dairy cows need $14-15$ hours of resting time. Providing an environment that is very comfortable (entices animal to lie down and rest/ruminate) to optimize her feed nutrients for animal health and performance, and clean, dry, and safe to minimize disease risks and injuries is imperative.

\section{Animal - Environment - People Interactions}

While our focus is on optimizing the health and performance of dairy animals through proper nutrition,

\footnotetext{
${ }^{1}$ Department of Animal Science, lowa State University, Ames, lowa, 50011, United States. Email Itimms@iastate.edu
} 
environment, and best management practices, it must be remembered that people are the essential caretaker of all of these. Proper attention to education and training of personnel, and implementation of best management practices to optimize all systems is paramount.

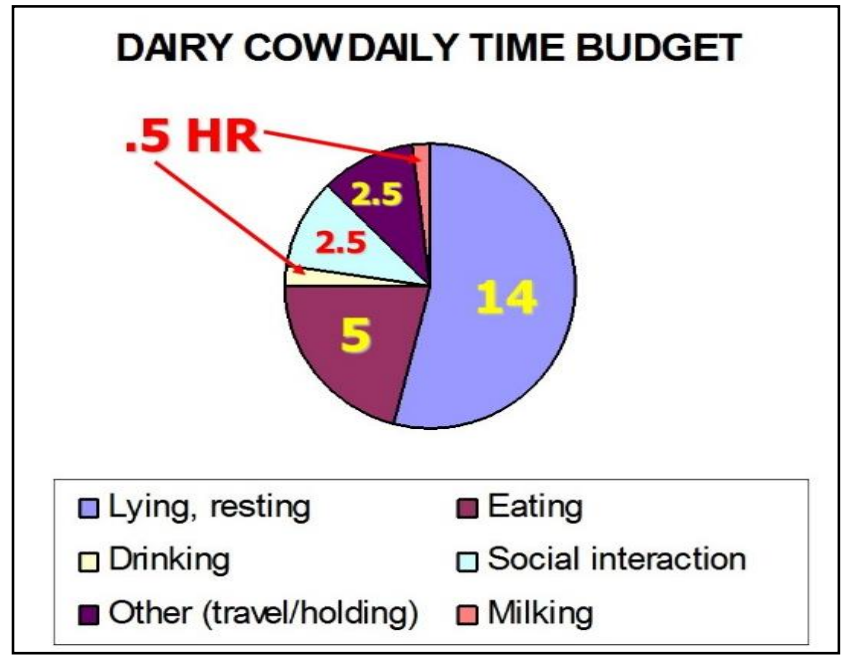

Figure 1. Dairy cow daily time budget.

Troubleshooting Milk Quality, Udder Health, and Mastitis: Don't Forget the Basics! Our overall goal is to have the highest quality milk with the lowest somatic cell count (SCC) and the least number of cows with SCC problems. When SCC becomes elevated and/or clinical mastitis escalates, we are often called upon to troubleshoot and evaluate on-farm milk quality practices and areas. People have developed many checklists and systematic approaches to evaluate these practices. When the evaluation or investigation is finished, we create a list of good or properly conducted procedures, and others that need attention. Sometimes we get too focused on the needs attention list (like wearing gloves). This may be an important practice (and I fully support the use of gloves), but if the data shows there is a fresh cow problem, wearing gloves is not the immediate issue or concern. Worse yet is that forcing glove use may decrease milker attitude and result in poorer milking and higher SCC.

While checklists are important, often troubleshooting is jumped into without examining the basics: a) What problem am I addressing: new or old?; b) What data do I have to help me ascertain the number of animals involved as well as new versus chronic cases?; c) What organisms are involved and does this new problem have similar or different organisms compared to past? Also, SCC can go up with no new cases, can go down with new cases, and will never go down unless existing infections or problem cows are dealt with. Too often, we jump to 2013 items on the checklist and make changes, without clearly laying out the whole problem and addressing cow and organism dynamics. This aspect of the paper and presentation will help us remember the basics when troubleshooting milk quality issues.

Highest milk quality = Lowest SCC = Lowest \# of problem animal

$\$ \$ \$=$ Prevent new cases of mastitid and decrease duration of existing cases (Schukken et al. 2003; Ruegg and Pantoja 2013)

1. Bulk Tank or DHI Weighted Average SCC: Bulk tank SCC is a measurement of $\leq 1 \mathrm{ml}$ of milk that represents all the cells and milk from all cows (and is hopefully then agitated properly). DHI weighted average SCC is really an overall weight or scale reading where every individual cow is weighted (SCC/ ml milk $\times$ volume of milk) and total cells/total volume (Figure 2). While this is an important number and we manage and get paid on it, this small fraction of milk does not inform us of how many problem cows (high SCC or clinical) we have, and whether they are old or new cases. Since individual cows are crucial to this overall measurement, the average SCC can also go up without any new cases (problem cows gain weight: higher SCC and / or more volume), go down and yet there are new cases, and will never go down unless problem cows are dealt with.

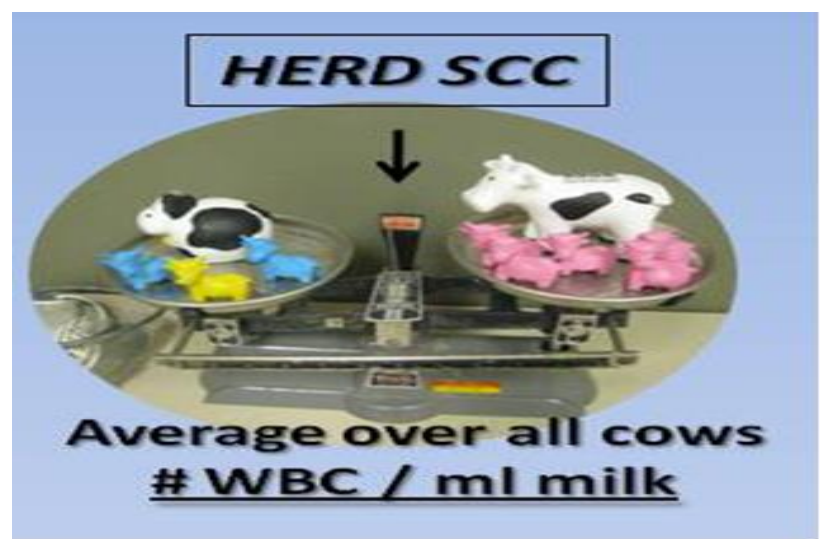

Figure 2. Weighted average herd somatic cell count (SCC) 
2. Individual Cow SCC: It is imperative that herds have individual SCC data. This allows a look at the size, scope, and dynamics of the problems. It is best to have monthly $\mathrm{DHI}$ data, but even some individual electronic tests or individual cow CMT's (California Mastitis Test) can work. There is no excuse for not having individual SCC. Individual cow data allows for categorizing cows (problem or not) as well as evaluating cow and herd dynamics (chronic vs. new cases; cured cases).

3. Defining a problem cow: A key step is defining what a problem SCC cow is what SCC level triggers attention (Figure 3)? Research supports that an individual cow SCC of $200,000 \mathrm{cells} / \mathrm{ml}$ (linear score 4) is the proper threshold and most $\mathrm{DHI}$ use this to put cows on the good or bad side of the scale. Some producers believe this is too low. It must be remembered that an individual cow SCC is a weighted average of four separate quarters and an SCC of 200,000 with three uninfected quarters $(<100,000)$ means the last infected quarter is $\geq 500,000$ cells $/ \mathrm{ml}$. (ie. a problem cow)!

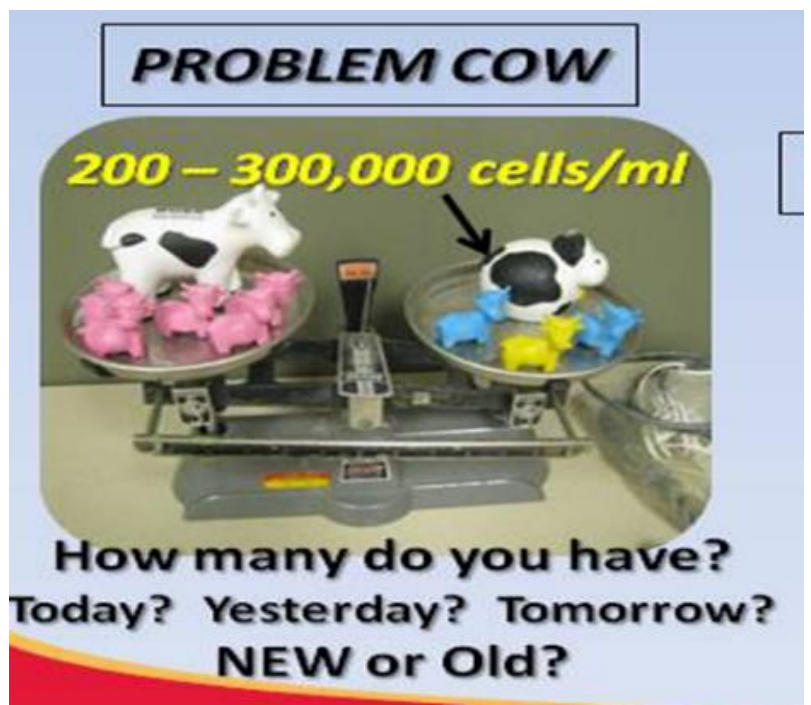

Figure 3. Defining a problem cow somatic cell count.

4. Cow impact on tank SCC: Remember that the cow's overall impact on tank SCC is her SCC (concentration) $\mathrm{X}$ her milk volume (Figure 4). Often times, people try to lower SCC by manipulating high SCC cows with low milk volume from the tank (dry off, etc.) This often results in no change and occasionally an increase in SCC.

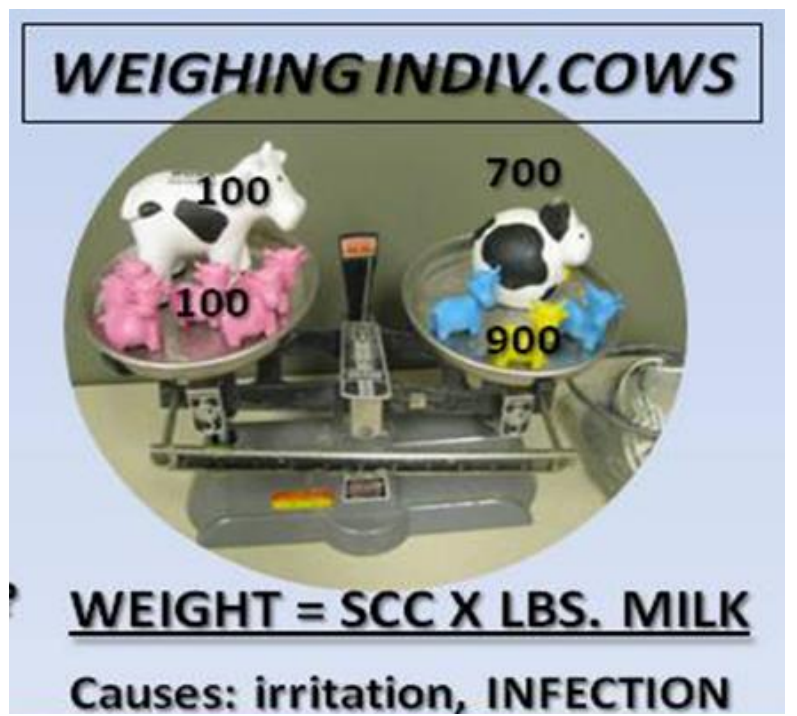

Figure 4. Individual cow impact on herd somatic cell count (SCC).

5. Monitoring individual cows (herd) with scatterplots. Visual scatterplots are often used to assess cow SCC dynamics (Figure 5). By plotting previous vs. current SCC, four distinct populations arise: uninfected (low for 2 months); chronic (high for 2 months); cured (high SCC now low); and new high SCC cows. Individual lactation groups can be represented differently and individual cows can often be identified by highlighting on the sign. One major problem with this is it misses one of the highest risk groups, fresh cows (only have 1 SCC).

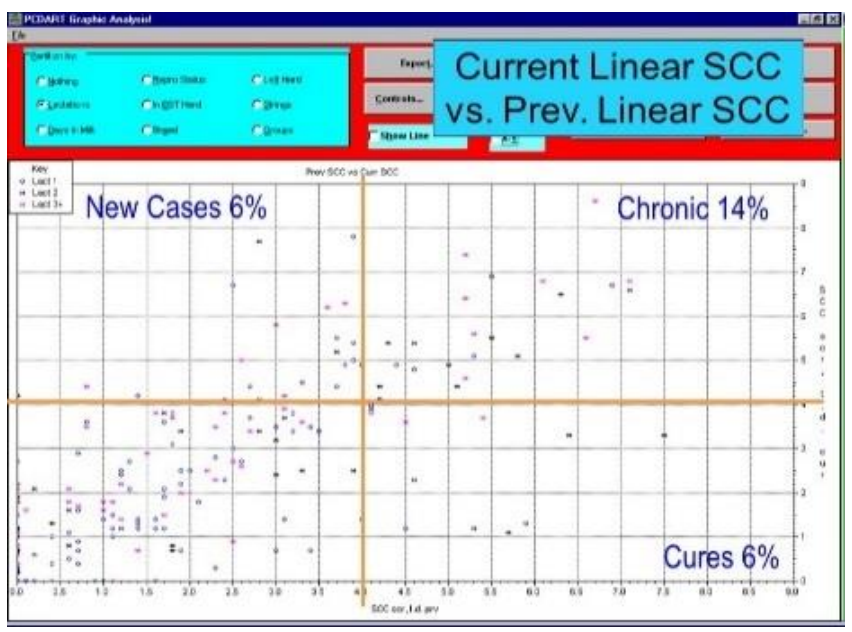

Figure 5. Monitoring individual cow (herd) somatic cell count. 
6. Monitoring Fresh Cows: Monitoring first test day SCC on fresh cows is excellent but may be well past calving date. Utilizing a CMT on fresh cows (Figure 6) offers a better, more timely observation. Key is to get the secretion (colostrum or thick milk) and CMT reagent to mix (get your fingers dirty) before swirling and reading. No gel has a negative predictive value (uninfected) of $>95 \%$. Presence of gelling only has a $25-50 \%$ positive predictive value for infection. SCC can be high due to IMI, or high in a protective role, especially on teats that are open prior to calving (heifers also) (Dingwell et al. 2003).

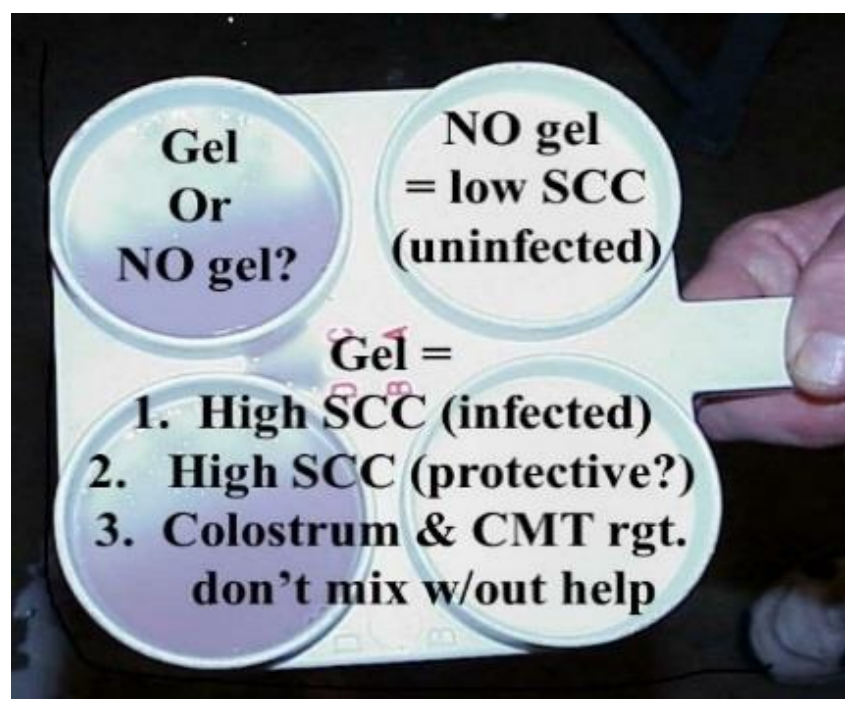

Figure 6. Monitoring fresh cows with CMT (California Mastitis Test) test.

7. Germ warfare: Know your organisms! High SCC means irritation and inflammation with $>99 \%$ due to infection. Routine bulk tank cultures can help but presence of contagious organisms does not define number of problem cows. Also, low bulk tank environmentals can mean excellent milker pre milking sanitation even in the face of environmental mastitis problems. Culturing individual problem cows (Figure 7) is most definitive in contagious and environmental, but also areas for prevention and therapy (Kelton and Godkin, 2000).

a) Staphylococcus. aureus: contagious; infected cows; milking practices; teat health since $S$. aureus is wound invader - especially critical for heifers, fresh cows, and winter! b) Environmental Streptococci; bedding and environment; look for teat end problems with Streptococcus. dysgalactiae.

c) Coliforms: fecal material and $\mathrm{H}_{2} \mathrm{O}$ ! These are poor skin colonizers but great swimmers and grow fast in milk!

d) Prototheca: Infected cows! Where's the water?

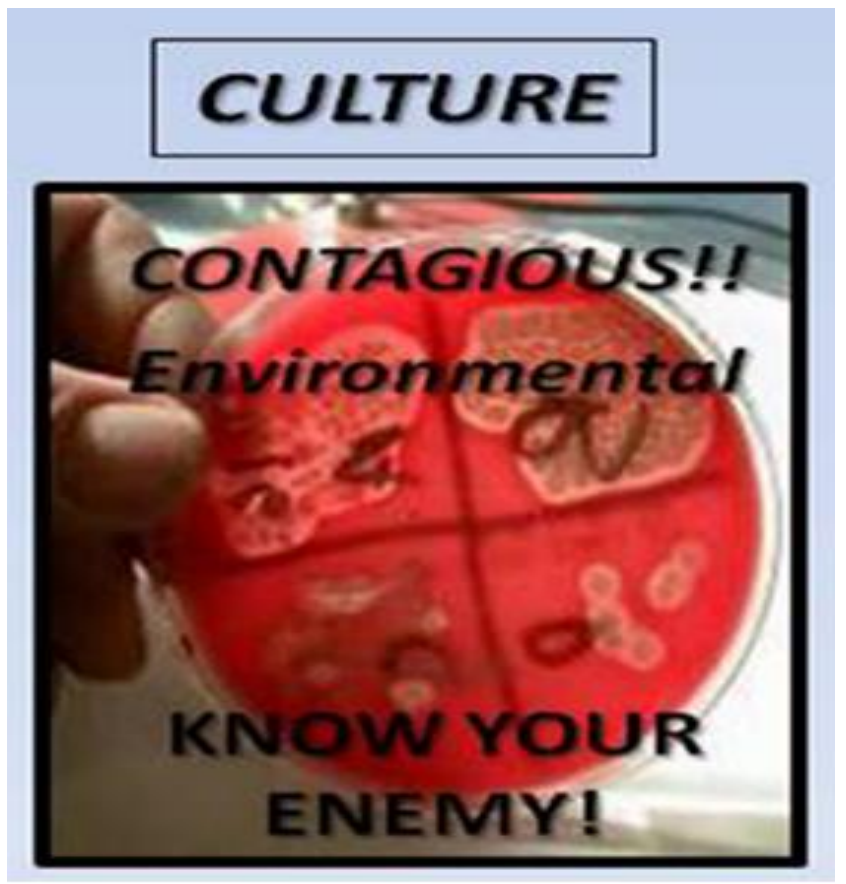

Figure 7. Culturing individual problem cows.

8. Mastitis: Pathogen - Host Interactions: (Figure 8) Mastitis occurs when a pathogen gets in the host and host reacts. The \#1 goal should $s$ be to minimize the bacterial numbers no matter what pathogen and this should happen all day in all areas where the animals are (not just at milking and not just milking cows). These pathogens interact or invade most times at a very specific spot (teat end or orifice) so evaluation of and attention to teat health is critical. Finally, a healthy host is critical, and clean cows and environment can still results in problem cows when the host's immune system is compromised. A clean, dry comfortable environment (14 hrs lying time) coupled to sound nutrition (5-6 hr eating time) and proper milking practices can minimize organism load and maximize immunity! 


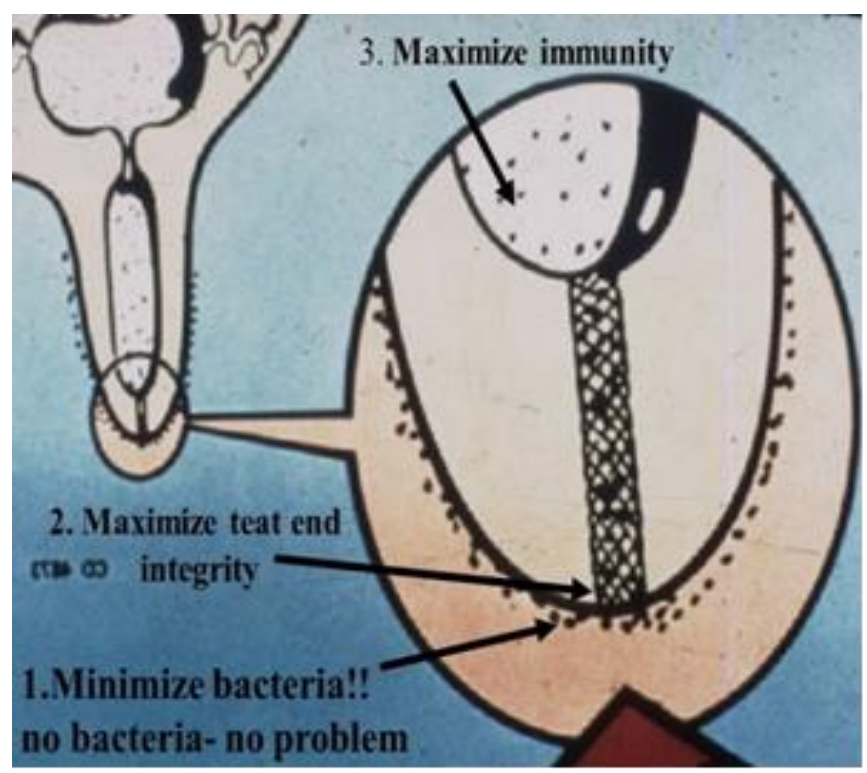

Figure 8. Mastitis pathogen - host interaction.

9. Dealing with Problem Cows: Prevention is \# 1 (Figures 9-11). This should be monitored and proven and may help SCC eventually go down but often keeps it from going up (SCC stays the same). This frustrates farmers who make many changes and their SCC remains stagnant. That is because they neglect to address problem cows (heavyweights) and make decisions to move them (Figure 9). This can be achieved by a variety of means including, spontaneous cure, treatment, dry off, selling, or segregating milk but decisions must be executed! Sometimes even praying helps.

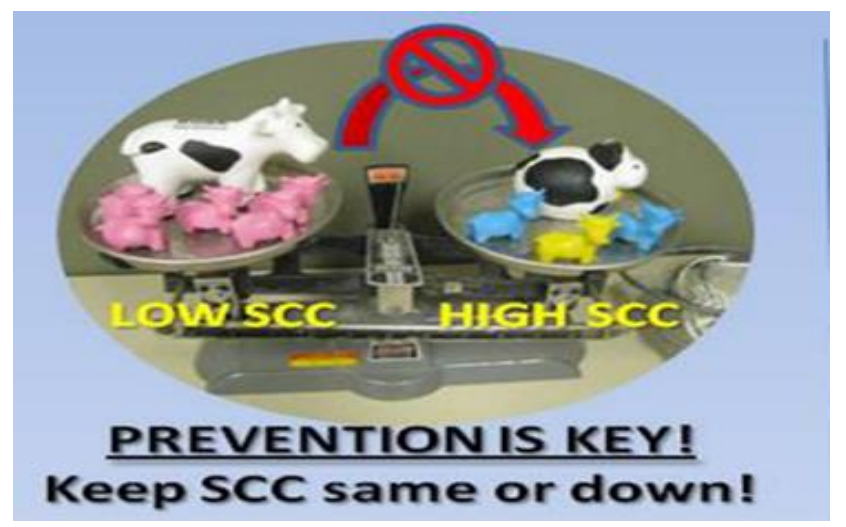

Figure 9. Mastitis prevention is key (stop new infections).

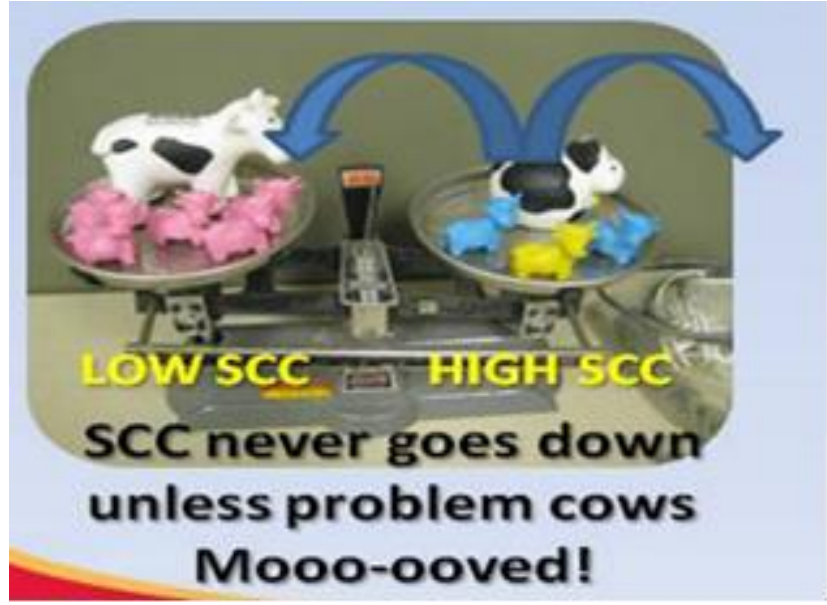

Figure 10. Move (deal with) problem cows to move (lower) somatic cell count.

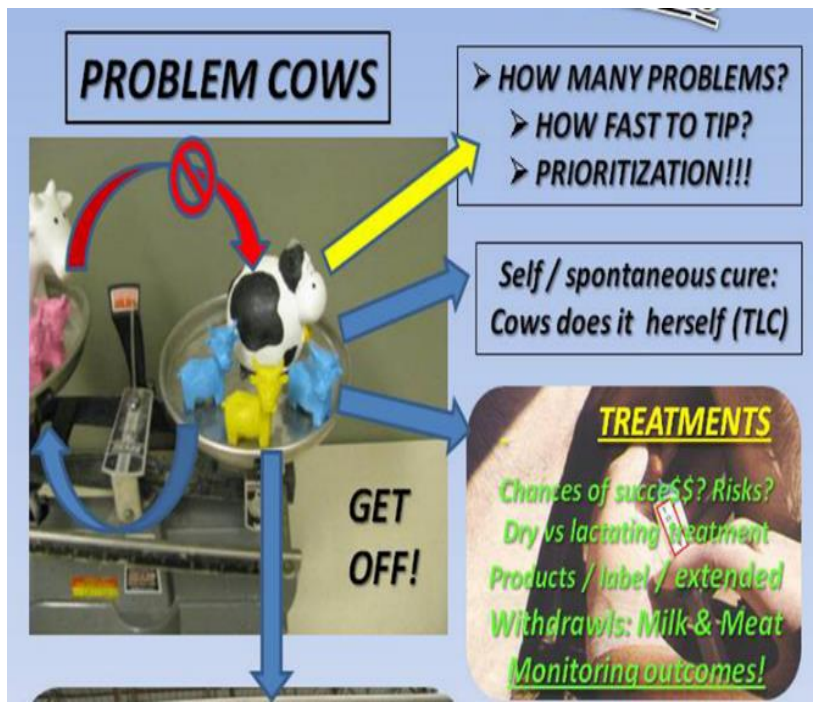

Figure 11. Decisions on mastitis problem cows.

10. Dealing with People as Well as Cows. While most of this paper and presentation focus on cows, it is ultimately the procedures and practices we implement and have in place consistently that make quality milk achievable. And people are the key! So make sure to look at the cows and the people, pay proper attention and training to both, and make sure the attitudes of both excel. So assess this last picture at milking: Cow - legs a little dirty but udder clean, milker - forestripping with no gloves! What is the problem? No gloves or dirty hands? (Figure 12). 


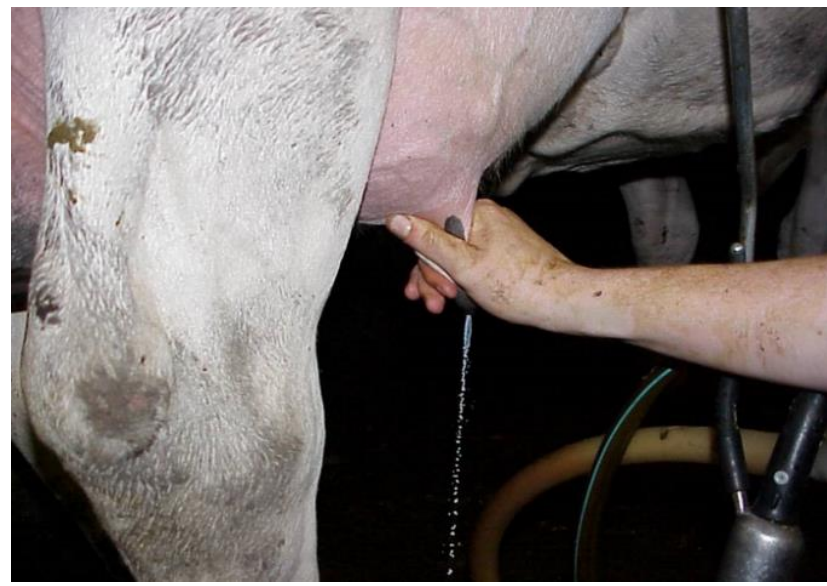

Figure 12. Problem? No gloves or dirty hands?

Harvesting milk. The efficient, proper harvest of milk is essential to maximize profitability by maximizing returns on investments made in breeding, feeding, housing, and caring for dairy animals. The primary goals of milk harvest or milking time are 1) obtain the highest quality and quantity of milk; 2) complete the task in an efficient amount of time; and 3) minimize risks of injury or mastitis to the mammary gland, and any injuries to milkers. This can only be achieved by understanding milk letdown process of the cow, and using proper milk harvesting techniques and equipment.

Milk letdown. The mammary gland is like a sponge where milk is continually made and fills up the alveoli and small ducts. The process of milk letdown allows this milk to be "wrung out" of the mammary gland. The milking routine must be organized to take maximum advantage of milk letdown.

When this is not achieved, less milk is harvested, it takes more time to milk, and unharvested milk can fuel mastitis organisms. This contradicts all milk harvest goals.

Preparing and sanitizing the teats prior to milking allows nerves in the teat to be stimulated. A nerve impulse is rapidly sent to the brain. The pituitary gland at the base of the brain releases oxytocin into the blood. Oxytocin then goes to the mammary gland, causing the myoepithelial cells to contract, thus creating pressure within the udder and forcing milk down to the teats.

Maximum oxytocin and pressure is achieved within
1 to 2 minutes. The kidney and liver remove oxytocin from the system, thus diminishing the oxytocin effect and a cow's cooperation after 4 to 7 minutes. It is imperative to attach a milker unit within 1 to 2 minutes after initiating stimulation in order to achieve complete yet rapid or efficient milkout $(<1$ min. may irritate teats; $>2$ min loses oxytocin response). It is also important to milk cows using a proper, consistent routine and comfortable environment since any stress or irritation results in the cow releasing a hormone, adrenaline, which blocks milk letdown.

\section{Proper Milking Practices and Procedures}

Proper milking practices are essential to insure rapid, complete milkout with minimal udder irritation or injury (NMC Research and Education 2013). They are also essential for maximal milk quality by minimizing external bacteria and other contaminants' from entering the milk or cow. A proper and comfortable milking environment is the first place to start. Establishment of a standard milking practices routine is important to assure all tasks are performed properly in a timely manner and similarly among all personnel responsible for milking. Both the milking machine and milker's hands should be sanitized prior to milking to minimize bacterial contamination and mastitis risks.

Premilking sanitation. Proper premilking sanitation and unit attachment practices account for $>85 \%$ of the keys to successful milk harvest. While there are many different ways for each step in premilking sanitation (sanitizing teats, different dips and sanitizers, drying apparatus and methods, etc.) and combination of practices, the critical key is to achieve all 8 key steps for full success (Johnson 2000).

1. Lowest bacterial count on teats prior to unit attach ( sanitize and dry, including teat ends)

2. Proper stimulation (10-15 seconds of pleasurable manual tactile teat stimulation!)

3. Properly forestrip teats (good stimulation) and examine milk for mastitis.

4. Minimize any risk of injury or trauma to cow and milkers.

5. Minimize any potential residues (must dry off dips and sanitizers).

6. Attach milker unit from 1-2 minutes from initiation of teat stimulation.

7. Optimize milker attachment and minimize slippage (dry teats and unit plumb under cow).

8. Be economical and cost effective but don't break any of the top 7 rules. 
Forestripping (stimulation) and checking for abnormal milk. A few streams of milk should be stripped into a strip cup or other place (parlor floor) that makes it easy to evaluate the milk for mastitis and abnormalities, but limits risk of future teat or animal contact (contagious mastitis spread). The purpose is to evaluate for abnormal milk and early mastitis detection. It also helps initiates milk letdown by providing 8-10 seconds of stimulation and removes a milk fraction that may be high in bacteria, sediment, and somatic cells. Rough stimulation and stripping inhibits milk letdown.

Stimulate and sanitize teats. This is best accomplished through a combination of a liquid or wash and a drying step. A minimal yet proper amount of wash water with sanitizer or preferably a premilking teat dip should be used since this will make it easier to dry. Excess moisture moves rather than removes bacteria to the teat. This liquid should be applied mainly on the teats since this is the area where the milker unit will touch. A minimum of 15 to 30 seconds of contact time is needed for adequate predip to achieve proper bacterial kill. Individual towels should be used to minimize infection spread. When predipping, use a clean dip cup with fresh dip. Teats should be reasonably clean before predipping and dip should cover the bottom $3 / 4$ of each teat.

Drying teats is an essential step. Teats should be thoroughly dried (with extreme focus on the teat end) with an individual towel or cloth to minimize any bacterial or chemical residues to the milk or cow, stimulate milk letdown (10 sec of stimulation), and reduce chances for teat cup slippage or squawking. This is important because when excess air is let in the teatcup like a squawk, this creates a vacuum fluctuation which is the major mechanism by which the milking machine can spread or influence mastitis.

\section{Milker Unit Handling.}

Milker unit attachment: The milker unit should be attached within 1 to 2 minutes after initiating stimulation to take maximum advantage of milk letdown. Excess air admission should be minimized to reduce agitation of the milk and mastitis risks.

Milking unit adjustment: Support and adjust milkers during milking if needed to assure proper milk out and minimize chances for air admission and liner squawks.

Machine stripping (minimize or OMIT). Although many operators feel it is essential to get every last drop of milk by massaging or stripping, this step has more potential risks than benefits. Machine stripping increases liner slips. Cows become trained to need this, and it reduces milker efficiency.

Milking unit removal or detaching: Shut off the vacuum and allow teat cups to gently fall off after milk flow slows or stops. Pulling teat cups off under vacuum injures the teat and is the single greatest risk of machine induced mastitis spread.

Post milking teat sanitation. Teats should be dipped immediately after unit removal with a safe, proven teat dip with an effective germicide. At least the bottom 3/4 of the teat should be covered on all sides to kill any bacteria in the film of milk where the unit was attached. Teat dip cups should be cleaned routinely and fresh dip used on every cow.

Animal cleanliness. Animal cleanliness, especially the rear legs and udders of dairy cows, is critical to optimize both mammary health as well as feet and leg health. Assessment and attention to animal cleanliness is critical. Increased cleanliness scores $(>2)$ have been associated with increased somatic cells and lower milk quality as well as poorer foot health, and are often indicative of poor environmental practices, or animals not resting where they should ( increased lameness risks). Goals are $>95 \%$ cleanliness score $\leq$ 2 ! Cleanliness scoring via a cow hygiene scoring card follows (Figure 13).

\section{Maximizing Feet and Leg Health: Lameness Identification, Prevention and Therapy}

Sound feet and legs are critical for animal performance and health. Limitations in mobility lead to decreased feed intakes, excessive lying or standing time, and often exacerbate further mobility, health, and production issues, including premature culling. Bovine lameness is one of the highest economic impacts on dairy farm economics. A system to properly and expediently define and categorize lameness, coupled with best management practices for both prevention and therapy are critical for optimizing feet and leg health and maximizing animal performance.

Lameness is a clinical sign of different diseases or disorders. For each condition, the range of causal risk factors and their severity varies; therefore, each condition has its own epidemiologic study. The importance of each factor differs depending on the system of management, be it total confinement, less restrictive systems, or totally pastoral. Management factors can usually be controlled, whereas factors such as ambient temperature, humidity, and rainfall must be taken into consideration but cannot be controlled. 
Diseases and disorders that affect the feet of dairy cows fall into two broad categories: those caused by infectious agents and those attributable to management.

The following variables can be controlled and are the focus of this paper and presentation: nutrition/water, walking surfaces, resting and stress (cow comfort, social confrontation, stocking density), cleanliness/hygiene - prevalence of infectious agents/moisture/irritants (discussed previously), human care (hoof trimming, lesion recording, directed foot treatments, foot bathing, farmer education), and genetic considerations.

If lameness has become a significant problem on a farm, it is invariably too late for a quick resolution. The first step is to immediately obtain the services of a competent hoof trimmer to assess and treat acute problems, while the critical part is to assess all lameness risks and implement best management practices to mitigate these risks.

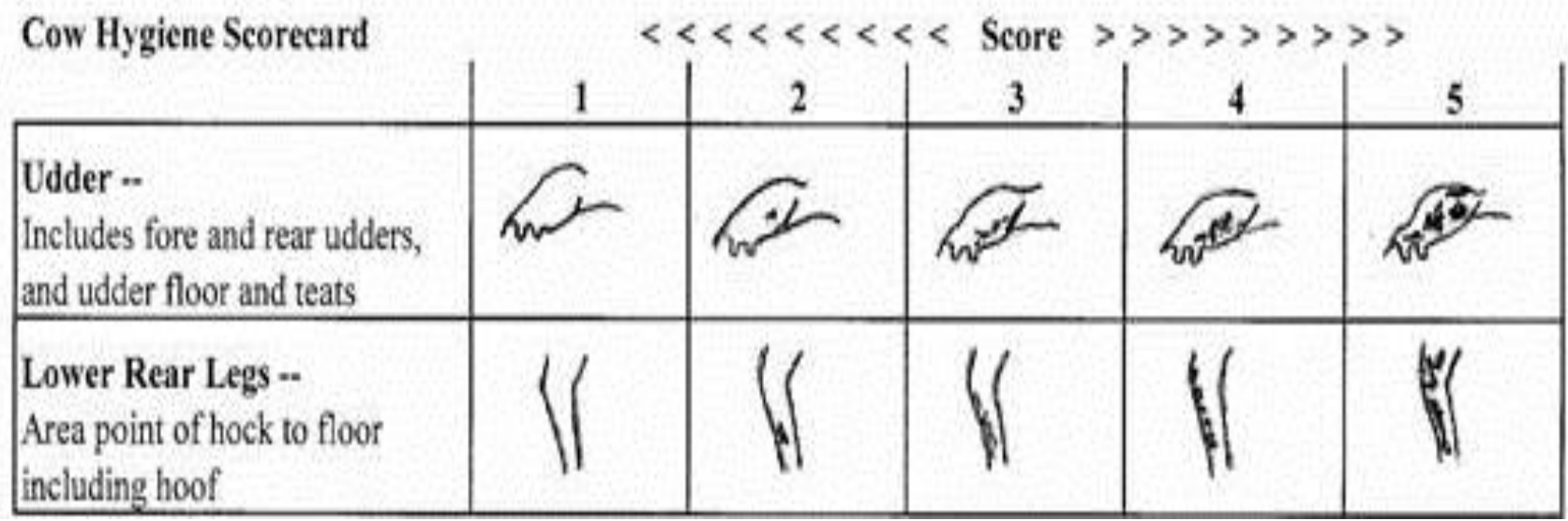

Figure 13. Cow hygiene scorecard.

Lameness detection or scoring. Designated times for observation and assessment of bovine lameness are critical. While it is important to observe clinical lameness or favoring of limbs when walking, small postural changes related to animals standing and their gait (walking) are early indicators of lameness and predisposing factors for clinical lameness unless proper practices are implemented.

Locomotion scoring is a useful tool as part of a routine herd health evaluation or in a detailed herd lameness investigation. Most farmers will detect between only 25 and $40 \%$ of truly lame cows; this underestimation of lameness prevalence means that the economic consequences of lame cows are less obvious to farmers than those caused by mastitis (loss of milk) and fertility problems. Cows in the early stages of sole ulcer, white line disease, and toe necrosis syndrome show only slight signs of lameness; if these lesions can be identified in their early stages, they can be treated and preventive measures instituted (Dairy Cattle Lameness Manual 2015).
Locomotion scoring identifies slightly lame cows as well as those more obviously lame (Table 1). Therefore, use of locomotion scoring can demonstrate the real extent of the problem.

Herd assessments should be done when the cows are walking on level, unobstructed walkways that give the observer a clear view. Locomotion scoring is frequently performed when the cows are leaving the milking parlor. In addition, milkers should note any cow standing in the milking parlor with an arched back, because it is highly probable that such cows are lame. Any cow lying down for an abnormally long time $(>70$ $80 \mathrm{~min} /$ bout) should also be noted for special attention.

As the locomotion score increases (3-5), milk yield decreases; however, composition of the milk (fat, protein) remains unaffected. A cow scoring 2 has decreased feed intake but may not drop milk production due to body weight loss, but has a $10 \mathrm{X}$ greater risk of scoring 3 if not addressed. Also, the repeatability of locomotion scoring is acceptably high among experienced observers. 
Table 1. Lameness (locomotion) scoring and clinical descriptions.

\begin{tabular}{|c|c|c|}
\hline $\begin{array}{l}\text { Lameness } \\
\text { Score }\end{array}$ & $\begin{array}{l}\text { Clinical } \\
\text { Description }\end{array}$ & Assessment Criteria \\
\hline 1 & Normal & $\begin{array}{l}\text { The cow stands and walks } \\
\text { with a level back posture. } \\
\text { Her gait is normal. }\end{array}$ \\
\hline 2 & Mildly lame & $\begin{array}{l}\text { The cow stands with a level } \\
\text { back posture, but develops } \\
\text { an arched back posture } \\
\text { while walking. Her gait is } \\
\text { normal. }\end{array}$ \\
\hline 3 & $\begin{array}{l}\text { Moderately } \\
\text { lame }\end{array}$ & $\begin{array}{l}\text { An arched back posture is } \\
\text { evident both while standing } \\
\text { and walking. Her gait is } \\
\text { affected and is vest } \\
\text { described as short striding } \\
\text { with one or more limbs. }\end{array}$ \\
\hline 4 & Lame & $\begin{array}{l}\text { An arched back posture is } \\
\text { always evident and gait is } \\
\text { best described as one } \\
\text { deliberate step at a time. } \\
\text { The cow favors one or more } \\
\text { limbs or feet. }\end{array}$ \\
\hline 5 & $\begin{array}{l}\text { Severe } \\
\text { lameness }\end{array}$ & $\begin{array}{l}\text { The cow additionally } \\
\text { demonstrates an inability or } \\
\text { extreme reluctance to bear } \\
\text { weight on one or more of } \\
\text { her limbs or feet. }\end{array}$ \\
\hline
\end{tabular}

Heritability of feet and leg traits, hoof lesions, and locomotion. Heritability estimates for feet and leg traits (side and rear view of rear legs, foot angle, feet and leg scores) range from $0.11-0.24$ depending on trait measured. Although there are more highly heritable traits (milk production, milk components), consideration of feet and leg traits weighted properly in a breeding index are useful for functional locomotion and longevity. Heritability for different foot lesions vary (0.01- 0.09) depending on lesions but are highly variable and hard to select for. Overall locomotion heritability is low $(0.03)$ due to all the multiple factors involved in locomotion, so focusing on functional feet and leg traits is the recommended selection tool (Laursen et al. 2009).

\section{Proper Nutrition}

Proper nutrition (feeds and ingredients, rations, mixing and delivery, adequate and clean feed bunks spaces) are all critical for animal health and performance. Rations must be balanced properly with individual ingredients, but then delivered to the animal, and animal must have all capabilities of consuming that diet properly (amount of feed, adequate space for all animals to eat, as well as minimizing issues of sorting, slug feeding, and other risks). Certainly all nutrients $\left(\mathrm{H}_{2} \mathrm{O}\right.$, carbohydrates (non-structural (NSC) like sugar and starch; structural like NDF and ADF), proteins, minerals (especially trace minerals), and vitamins are crucial. It is not the focus of this paper to address all nutrients, but rather a few situations.

Protein. Amount of protein in the ration has been suggested to influence incidence of laminitis. Several studies have shown that high percentages of ruminally degraded protein (RDP) identified in association with lameness and laminitis. However, the role of protein is still unclear. Also, although low RDP is not associated with lameness, low RDP usually leads to low microbial protein and lower milk urea nitrogen $(M U N<8)$ which impacts in lower milk production, milk protein, and lower overall immunity ( which can then impact udder and hoof health).

Carbohydrates (non- structural and structural). Subacute ruminal acidosis (SARA) is a common problem in many dairy herds that can manifest itself in a variety of symptoms including lower milk and components, variable manure, variable feed intakes, decreased immunity, and lameness or laminitis (inflammation of the bone area within the foot). Successfully managing SARA depends on the quantity and digestibility of the carbohydrate fed. The more rapidly NSC is digested in the rumen, the more rapidly rumen acidosis may develop if adequate functional fiber is not available to provide a rumen mat and rumen buffering through saliva. Finely ground or moist grains are more digestible than dry, cracked grain. Corn silage is frequently used in dairy production, with the energy content and/or digestibility completely underestimated. Slug feeding once a day is contraindicated, and the more frequently concentrates are fed the better. Sudden changes in the diet or 
formulation of the diet can also affect nutrient flow and digestion. The quality and quantity of fiber fed could be as or more important than the NSC component of the diet. Fiber can, depending on its physical characteristics, stimulate rumination. If the carbohydrate:fiber ratio is $>50 \%$ carbohydrate, the animal is increasingly at risk of ruminal acidosis. If the percentage of acid detergent fiber for the complete ration is $<20 \%$, risk of ruminal acidosis also increases. If the particle length of silage is cut too short $(25 \%$ cut $<5 \mathrm{~cm}$ long), contribution of effective fiber is reduced. Rations should be balanced for ADF, NDF, NSC, and physical form and digestibility of forages and total diet.

The manure should not contain fiber particles $<1$ $\mathrm{cm}$ of undigested grain. This can be checked by placing 2 cups of manure in a fine mesh kitchen sieve and washing the material through with water from a hose. Feces should not contain mucin/fibrin casts, be foamy, or contain gas bubbles. The feces in the same feeding group should consistent (4-5 concentric rings and stack 2-4") and not vary from firm to diarrhea (Merck Veterinary Manual, 2015).

\section{Walking Surfaces}

Walking surfaces are another important contributing cause of lameness. Efforts should focus on making sure all walking surfaces have excellent footing, comfort (as much as possible), and minimize risks of injuries (slippage, abrasive surfaces or rocks/ stones, etc).

Cow housing, resting, stress, cow comfort, social confrontation, stocking density. Under normal conditions, a healthy cow rests 14 hrs day (lying down 11-13 hr/day). Cows have 8-10 resting periods/ day with each resting period usually lasting just longer than $1 \mathrm{hr}$, during which time the cows ruminate and thus digest their feed. Lameness, depending on its severity, tends to increase both the lying time and the number of lying bouts (but has also been shown to increase standing time depending on the stall surface). Anything that inhibits a cow from lying down the appropriate amount of time is concerning. This can encompass improper stall or lying space dimension, uncomfortable surfaces, laminitis (due to feeding issues), or overcrowding (overstocking) which forces animals to stand (or lie in inappropriate places). All of these issues should be optimized to minimize feet and leg and all other problems, and assure animal health.
These risk factors together with other physical stressors have been referred to as ecopathologic factors or an Animal Suitability Index. These terms refer to an assessment tool for housing conditions based on seven spheres of influence: walking, feeding, socializing, resting and comfort, behavior, hygiene, and care. Ecopathology, therefore, is evaluation of space allowance, cubicle dimensions, stall base, bedding, stall and pen measurements, type of flooring, slipperiness, stocking density, cleanliness, hoof trimming and foot bathing, feed bunk space, water supply, walking surface conditions, and mobility locomotion score. (Merck Veterinary Manual, 2015).

Foot or hoof trimming. Over time, the claws of cows wear, changing the shape of the sole, which in turn makes the foot unstable. The two claws become unbalanced both longitudinally and laterally. As changes occur in the lateral claw, it becomes overloaded, the heel horn may become thicker (overburdened), and posture is compromised. Therefore, the objective of trimming is to reduce excessive weight bearing on load-bearing claws, and balance the weight bearing across claws, feet, and legs. Under normal circumstances, horn growth keeps pace with wear. The growth/wear rate at the heel is greater than at the toe. Horn that is dry tends to be extremely resistant to wear and may grow longer than normal. Thus, the claws of cattle maintained in straw yards tend to become overgrown. Conversely, the claws of cattle maintained in extremely wet conditions are softer than normal and more prone to wear and damage. If the cows are housed on concrete surfaces, the lateral hind claw tends to wear less than the medial.

Foot evaluation and trimming of every cow should be performed at least once/year (twice preferred). Recording and reporting any abnormalities and types of lesions observed will prompt early treatment and timely introduction of preventive measures (Shearer and van Amstel 2015).

\section{Summary}

Optimizing udder and feet and leg health is critical to overall animal health and performance, and dairy profitability. Having systems in place to easily monitor and evaluate udder and mammary health (SCC, CMT, culture), and feet and leg health (locomotion or lameness scoring), coupled with overall animal health 
and risk metrics (cleanliness scoring, body condition scoring, feed intake, milk production and components) are essential elements for dairy success. Best management practices for prevention (nutrition including both feed and water, proper housing and environment to maximize dry matter intake and resting/ lying times while minimizing injury risks, milking practices, and hoof care (including routine trimming) are essential pillars for this success. Therapy or treatment is after the fact where a breakdown or weakness has occurred. When therapy is needed and appropriate, it should be based on sound science, evidence and causation based, and be in conjunction with veterinary or animal health professionals.

\section{References Cited}

Dairy Cattle Lameness Manual. 2015. http://www.zinpro.com/lameness/dairy

Dingwell R.T., K.E. Leslie, Y.H. Schukken, J.M. Sargent, and L.L. Timms. 2003. Evaluation of the California mastitis test to detect an intramammary infection with a major pathogen in early lactation dairy cows. Canadian Veterinary Journal 44:413.

Johnson, A.P. 2000. A proper milking routine: the key to quality milk. National Mastitis Council Annual Proceedings 123.
Kelton, D.F., and M.A. Godkin. 2000. Mastitis culture programs for dairy herds. National Mastitis Council Annual Proceedings 54.

Lameness in Dairy Cattle. 2015. Merck Veterinary Manual. http://www.merckvetmanual.com/mvm/musculoskeletal system/lameness in cattle/overview of lameness in $\mathrm{C}$ attle.html

Laursen, M.V., D. Boelling, and T. Mark. 2009. Genetic parameters for claw and leg health, foot and leg conformation, and locomotion in Danish Holsteins. Journal of Dairy Science 92:1770.

NMC Research and Education. 2013. Recommended milking procedures. National Mastitis Council Online. https.//nmconline.org/milkprd.htm

Ruegg, P.L., and J.C.F. Pantoja. 2013. Understanding and using somatic cell counts to improve milk quality. Irish Journal of Agriculture and Food Research 52:101.

Schukken, Y.H., D.J. Wilson, F. Welcome, L. GarrisonTikofsky, and R.N. Gonzalez. 2003. Monitoring udder health and milk quality using somatic cell counts. Veterinary Research 34:579.

Shearer, J., and S. van Amstel. 2015. Manual of foot care in cattle. Hoard's Dairyman Publications. http://www.hoards.com/bookstore/FOOT2

Recieved for publication on April 5, 2016.

Accepted for publication on July 18, 2016. 